\title{
Author Correction: Every step of the way: integrins in cancer progression and metastasis
}

\section{Hellyeh Hamidi and Johanna Ivaska}

Nature Reviews Cancer (2018) https://doi.org/10.1038/s41568-018-0038-z

Published online 12 July 2018

In the originally published article, pertuzumab was incorrectly described as an anti-PI3K therapy in the section 'Integrins in anticancer therapy'. The sentence should read, "In mouse mammary tumour models, increased collagen levels and increased $\beta 1$ integrin and SRC activity have been demonstrated to accompany, and promote, combined resistance to anti-human epidermal growth factor receptor 2 (HER2; also known as ERBB2) (trastuzumab and pertuzumab) and anti-PI3K (buparlisib) therapies ${ }^{164}$." This has now been corrected in all versions of the original article.

https://doi.org/10.1038/s41568-019-0112-1 I Published online 31 January 2019 